\title{
Thermal Error Modeling of a Machining Center Using Grey System Theory and Adaptive Network-Based Fuzzy Inference System*
}

\author{
Kun-Chieh WANG**, Pai-Chung TSENG ${ }^{* * *}$ and Kuo-Ming LIN**
}

\begin{abstract}
Thermal effect on machine tools is a well-recognized problem in an environment of increasing demand for product quality. The performance of a thermal error compensation system typically depends on the accuracy and robustness of the thermal error model. This work presents a novel thermal error model utilizing two mathematic schemes: the grey system theory and the adaptive network-based fuzzy inference system (ANFIS). First, the measured temperature and deformation results are analyzed via the grey system theory to obtain the influence ranking of temperature ascent on thermal drift of spindle. Then, using the highly ranked temperature ascents as inputs for the ANFIS and training these data by the hybrid learning rule, a thermal compensation model is constructed. The grey system theory effectively reduces the number of temperature sensors needed on a machine structure for prediction, and the ANFIS has the advantages of good accuracy and robustness. For testing the performance of proposed ANFIS model, a real-cutting operation test was conducted. Comparison results demonstrate that the modeling schemes of the ANFIS coupled with the grey system theory has good predictive ability.
\end{abstract}

Key Words: Grey System Theory, Adaptive Network-Based Fuzzy Inference System, Artificial Neural Network, CNC Machine Tools, Thermal Error Compensation

\section{Introduction}

The tool machinery's thermal behavior is recognized as one of the major reasons for work piece inaccuracies. In developing precision machinery, the studies in the patterns of tool machinery's thermal deformation and procedures to reduce the thermal deformation are significant to the improvement of processing precision. The compensation for thermal deformation can be direct and indirect. Direct compensation is made immediately to the errors detected on-line. However, it is rather difficult to detect the errors in this way so the method is currently used only in laboratory. Indirect compensation detects the machinery's repetitive and foreseeable errors off-line, and then builds error tables or mathematical models for errors as an er-

* Received 22nd February, 2006 (No. 06-5028)

** Department of Technological Product Design, Ling Tung University, 1 Lingtung Road, Nantun, 40852, Taichungcity, Taiwan, R.O.C. E-mail: kcwang@mail.ltu.edu.tw

*** Department of Mechanical Engineering, National Chung Hsing University, 24 Ping-An St., Changhua-city, Changhua County, 500, Taiwan, R.O.C. ror database that will be used to determine compensation in processing. Due to its low cost and practical feature, the indirect compensation becomes ever widely applied. In indirect compensation, the development of forecasting model for heat errors is most important. Therefore the reliability of the model is always the focus and goal of relevant studies. The methodology for heat error forecasting of tool machinery usually employs the model describing the relationship between temperature ascent and thermal deformation, applies experimental data to train this model, and predicts the machine's thermal deformation in processing.

Excessive research has been carried out in the past in the area of thermal error modeling ${ }^{(1)-(19)}$. There are two main research areas related to thermal error modeling. The first area is numerical analysis techniques such as the finite element method $^{(1)}$ and finite difference method ${ }^{(2)}$. These techniques are restricted to a qualitative analysis because the boundary conditions and heat transfer characteristics cannot be clearly defined. The second area is empirical modeling based on the measurement of thermal deformation and temperature at discrete representative points on 
the machine tools. Examples include engineering judgment $^{(3)}$, regression analysis ${ }^{(5)}$, neural network ${ }^{(6)-(8)}$, grey system theory ${ }^{(12)}$, and fuzzy logic ${ }^{(15)}$. Empirical models have been demonstrated to show satisfactory prediction accuracy in many applications even though each method has its own shortcomings.

Among the empirical models, the fuzzy logic schemes do not require detailed information regarding the characteristic of the manufacturing plant and has a consequence structure in the format of a linear equation. This linear equation is more robust against measurement noises than an engineering judgment model, which includes high-order variables. However, fuzzy systems lack the ability to learn or adjust themselves to new environments. On the other hand, although neural networks can learn, they are opaque to users. Merging a neural network with a fuzzy system into an integrated system therefore is a promising technique for building intelligent systems. Since an integrated neuro-fuzzy systems (ANFIS) combines the advantages of parallel computational and learning abilities of neural networks with the human-like knowledge representation and explanatory capabilities of fuzzy systems, this work attempts to utilize this system to establish an accurate thermal error model.

First proposed by Jang ${ }^{(24)}$, the ANFIS employs an adaptive network. Functionally, almost no constraints, other than the requirement for piecewise differentiability, exist for node functions in an adaptive network. Structurally, the only limitation on the network configuration is that it must be feed-forward. Because of these minimal restrictions, adaptive networks can be employed directly in a wide variety of applications such as modeling, decision making, signal processing, and control.

On the other hand, it is commonly known that placing a large number of thermal sensors on a machine structure improves the accuracy and robustness of a thermal error model. However, engineers continually seek to reduce the number of temperature sensors required. Some studies have used statistical methods, such as correlation analysis $^{(20)}$, standard stepwise regression ${ }^{(21)}$, correlation group$\operatorname{ing}^{(22)}$, and dynamic thermal error modeling ${ }^{(23)}$, to determine temperature variables for the thermal error models. In this study, a different approach is proposed to efficiently overcome this difficulty. First, the grey system theory is used to evaluate the influence weighting of temperature ascents at critical points on a machine structure against the thermal drift of a spindle. Then, by choosing a few high-ranking temperature ascents, combined with synchronously measured thermal drift data, the 'temperatureerror' mapping can be carried out by the ANFIS. A brief explanation of the theories of grey system and ANFIS is provided in the next sections.

\section{Methodology of Thermal Error Model}

This study focuses on the development of the ANFIS compensation model for machinery thermal error estimation and the grey system theory for reduction/selection of the characteristic points on a machine structure for temperature measurement. These methodologies are explained in the following sections.

\section{1 $\operatorname{GM}(1, N)$ model}

The theory of the grey system is based on the assumption that a system is uncertain, and that the information regarding the system is insufficient to build a relational analysis or to construct a model to characterize the system ${ }^{(25)}$. The grey system puts each stochastic variable as a grey quantity that changes within a given range. It does not rely on statistical method to deal with the grey quantity. It deals directly with the original data, and searches the intrinsic regularity of data ${ }^{(12)}$. The grey system theory include the following fields: (a) grey generating, (b) grey relational analysis, (c) grey forecasting, (d) grey decision making, and (e) grey control.

In grey system, the irregular data are transformed into new data sets with strong regularity by using a data generation scheme called the accumulated generating operation (AGO). The more the times of accumulation, the more evidently can the data series be described by the exponential function.

The general format of the grey system model is

$$
\begin{gathered}
\frac{d^{M} x_{1}^{(i)}(k)}{d t^{M}}+a_{1} \frac{d^{M-1} x_{1}^{(i)}(k)}{d t^{M-1}}+\cdots+a_{M} x_{1}^{(i)}(k) \\
=b_{2} x_{2}^{(i)}(k)+b_{3} x_{3}^{(i)}(k)+\cdots+b_{N} x_{N}^{(i)}(k),
\end{gathered}
$$

where $M$ is the order of the differential equation and $N$ is the number of the types of the data. Equation (1) is called a grey dynamic model, commonly denoted as $\operatorname{GM}(M, N)$. The coefficients of the model are estimated by the least-square method. In this research, the $\operatorname{GM}(1, N)$ model is used to describe the relationship between the spindle thermal drift and the temperature rise at characteristic monitoring points. Considering the sequences $x_{i}^{(0)}(k), i=1,2,3, \cdots N$ and $k=1,2,3, \ldots, n$ in which $x_{1}^{(0)}(k)$ is the main factor in the system (spindle thermal drifts) and $x_{2}^{(0)}(k), x_{3}^{(0)}(k), \ldots, x_{N}^{(0)}(k)$ represent the influence factors (temperature rises), then the $\operatorname{GM}(1, N)$ model can be defined as

$$
x_{1}^{(0)}(k)+a_{1} z_{1}^{(1)}(k)=\sum_{j=2}^{N} b_{j} x_{j}^{(1)}(k), k=1,2,3, \ldots, n .
$$

Followings are the manipulating procedures for $\operatorname{GM}(1, N)$. Step 1 Build the initial sequences:

$$
x_{i}^{(0)}(k), i=1,2,3, \cdots N \text { and } k=1,2,3, \ldots, n .
$$

Step 2 Generate the new sequences $x_{i}^{(1)}(k)$ by AGO method based on the initial sequences $x_{i}^{(0)}(k)$;

$$
A G O\left\{x_{i}^{(0)}\right\}=x_{i}^{(1)}=\left\{x_{i}^{(1)}(k)\right\},
$$


where

$$
x_{i}^{(1)}(k)=\sum_{j=1}^{k} x_{i}^{(0)}(j), i=1,2,3, \ldots, N \text { and } k=1,2,3, \ldots, n .
$$

Step 3 Assume the following first-order differential equation holds true:

$$
\begin{aligned}
& \frac{d x_{1}^{(0)}(k)}{d t}+a x_{1}^{(1)}(k) \\
& \quad=b_{2} x_{2}^{(1)}(k)+b_{3} x_{3}^{(1)}(k)+\cdots+b_{N} x_{N}^{(1)}(k), k=2,3, \ldots, n .
\end{aligned}
$$

Step 4 Solve Eq. (6) by difference approximation and combine with Eq. (5) to yield

$$
x_{1}^{(0)}(k)+a z_{1}^{(1)}(k)=\sum_{j=2}^{N} b_{j} x_{j}^{(1)}(k), k=2,3, \ldots, n .
$$

where

$$
z_{1}^{(1)}(k)=0.5 x_{1}^{(1)}(k)+0.5 x_{1}^{(1)}(k-1), k=2,3, \ldots, n .
$$

Rearrange Eq. (7) in matrix form as

$$
Y_{N}=B \hat{a},
$$

where

$$
\begin{aligned}
& Y_{N}=\left[\begin{array}{l}
x_{1}^{(0)}(2) \\
x_{1}^{(0)}(3) \\
\vdots \\
x_{1}^{(0)}(n)
\end{array}\right], \quad \hat{a}=\left[\begin{array}{c}
a \\
b_{2} \\
\vdots \\
b_{N}
\end{array}\right], \\
& B=\left[\begin{array}{llll}
-z_{1}^{(1)}(2) & x_{2}^{(1)}(2) & \cdots & x_{N}^{(1)}(2) \\
-z_{1}^{(1)}(3) & x_{2}^{(1)}(3) & \cdots & x_{N}^{(1)}(3) \\
\vdots & & & \\
-z_{1}^{(1)}(n) & x_{2}^{(1)}(n) & \cdots & x_{N}^{(1)}(n)
\end{array}\right] .
\end{aligned}
$$

Step 5 Estimate $\hat{a}$ by using the least-square error method as

$$
\hat{a}=\left(B^{T} B\right)^{-1} B^{T} Y_{N} .
$$

Hence, the influence ranking of the major sequences on the target sequences can be found by comparing the norm values of $b_{2} \sim b_{N}$.

\subsection{ANFIS}

2.2.1 Architecture For simplicity, assuming that the fuzzy inference system under consideration has two inputs $x$ and $y$ and one output $z$. For a first-order Sugeno fuzzy model, a common rule set with two fuzzy if-then rules is as following:

Rule 1: If $x$ is $A_{1}$ and $y$ is $B_{1}$, then $f_{1}=p_{1} x+q_{1} y+r_{1}$,

Rule 2: If $x$ is $A_{2}$ and $y$ is $B_{2}$, then $f_{2}=p_{2} x+q_{2} y+r_{2}$. Figure 1 (a) illustrates the reasoning mechanism for this Sugeno model; the corresponding equivalent ANFIS architecture is shown in Fig. 1 (b), where nodes of the same layer have similar functions, as described next. (Here we denote the output of the $i$ th node in layer 1 as $O_{l, i}$.)

Layer 1 Every node $i$ in this layer is an adaptive node with a node function

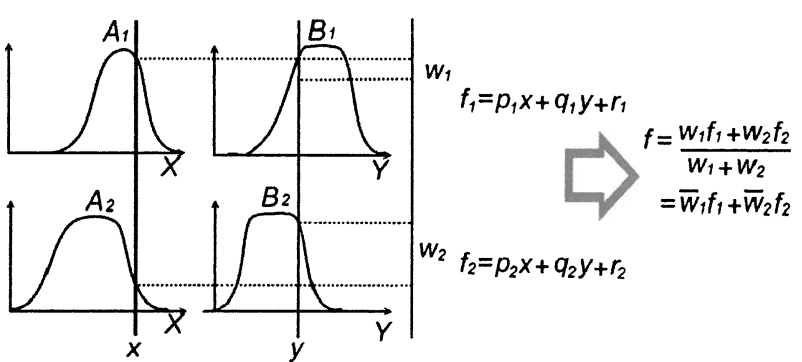

(a) A two-input first-order Sugeno fuzzy model with two rules

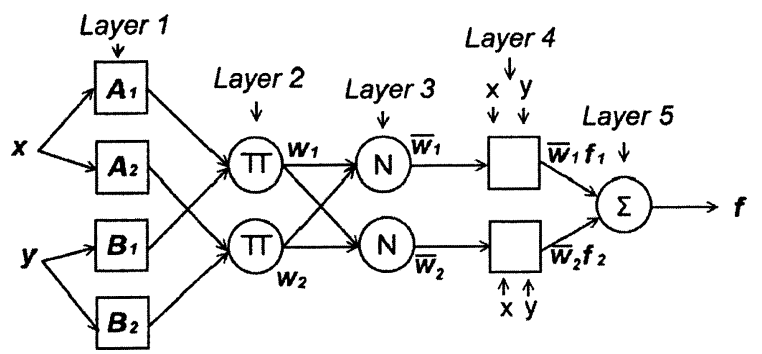

(b) Equivalent ANFIS architecture

Fig. 1 Reasoning mechanism of ANFIS

$$
\begin{gathered}
O_{l, i}=\mu A_{i}(x), \quad \text { for } i=1,2, \text { or } \\
O_{l, i}=\mu B_{i-2}(y), \quad \text { for } i=3,4,
\end{gathered}
$$

where $x$ (or $y$ ) is the input to node $i$ and $A_{i}$ (or $B_{i-2}$ ) is a linguistic label (such as "small" or "large") associated with this node. In other words, $O_{l, i}$ is the membership grade of a fuzzy set $A\left(=A_{1}, A_{2}, B_{1}\right.$ or $\left.B_{2}\right)$ and it specifies the degree to which the given input $x$ (or $y$ ) satisfies the quantifier $A$. Here the membership function for $A$ is chosen as the generalized bell function:

$$
\mu A(x)=\frac{1}{1+\left|\frac{x-c_{i}}{a_{i}}\right|^{2 b_{i}}},
$$

where $\left\{a_{i}, b_{i}, c_{i}\right\}$ is the parameter set. Parameters in this layer are referred to as premise parameters.

Layer 2 Every node in this layer is a fixed node labeled $\Pi$, whose output is the product of all the incoming signals:

$$
O_{2, i}=w_{i}=\mu A_{i}(x) \mu B_{i}(y), i=1,2 .
$$

Each node output represents the firing strength of a rule.

Layer 3 Every node in this layer is a fixed node labeled $N$. The $i$ th node calculates the ratio of the $i$ th rule's firing strength to the sum of all rules' firing strengths:

$$
O_{3, i}=\bar{w}_{i}=\frac{w_{i}}{w_{1}+w_{2}}, i=1,2 .
$$

For convenience, outputs of this layer are called normalized firing strengths.

Layer 4 Every node $i$ in this layer is an adaptive node with a node function

$$
O_{4, i}=\bar{w}_{i} f_{i}=\bar{w}_{i}\left(p_{i} x+q_{i} y+r_{i}\right),
$$

Where $\bar{w}_{i}$ is a normalized firing strength from layer 3 and $\left\{p_{i}, q_{i}, r_{i}\right\}$ is the parameter set of this node. Parameters in this layer are referred to as consequent parameters. 
Layer 5 The single node in this layer is a fixed node labeled $\Sigma$, which computes the overall output as the summation of all incoming signals:

$$
\text { overall output }=O_{5,1}=\sum_{i} \bar{w}_{i} f_{i}=\frac{\sum_{i} w_{i} f_{i}}{\sum_{i} w_{i}}
$$

2.2.2 Hybrid learning algorithm The hybrid learning rule combines steepest descent (SD) and the least-squares estimator (LES) for fast identification of parameters. The hybrid learning is applied in a batch mode here. Each epoch is composed of a forward pass and backward pass. In the forward pass of the hybrid learning algorithm, node outputs go least-square method. In the backward pass, the error signals propagate backward and the premise parameters are updated by gradient descent.

The consequent parameters thus identified are optimal under the condition that the premise parameters are fixed. Accordingly, the hybrid approach converges much faster since it reduces the search space dimensions of the original pure back-propagation method. The training

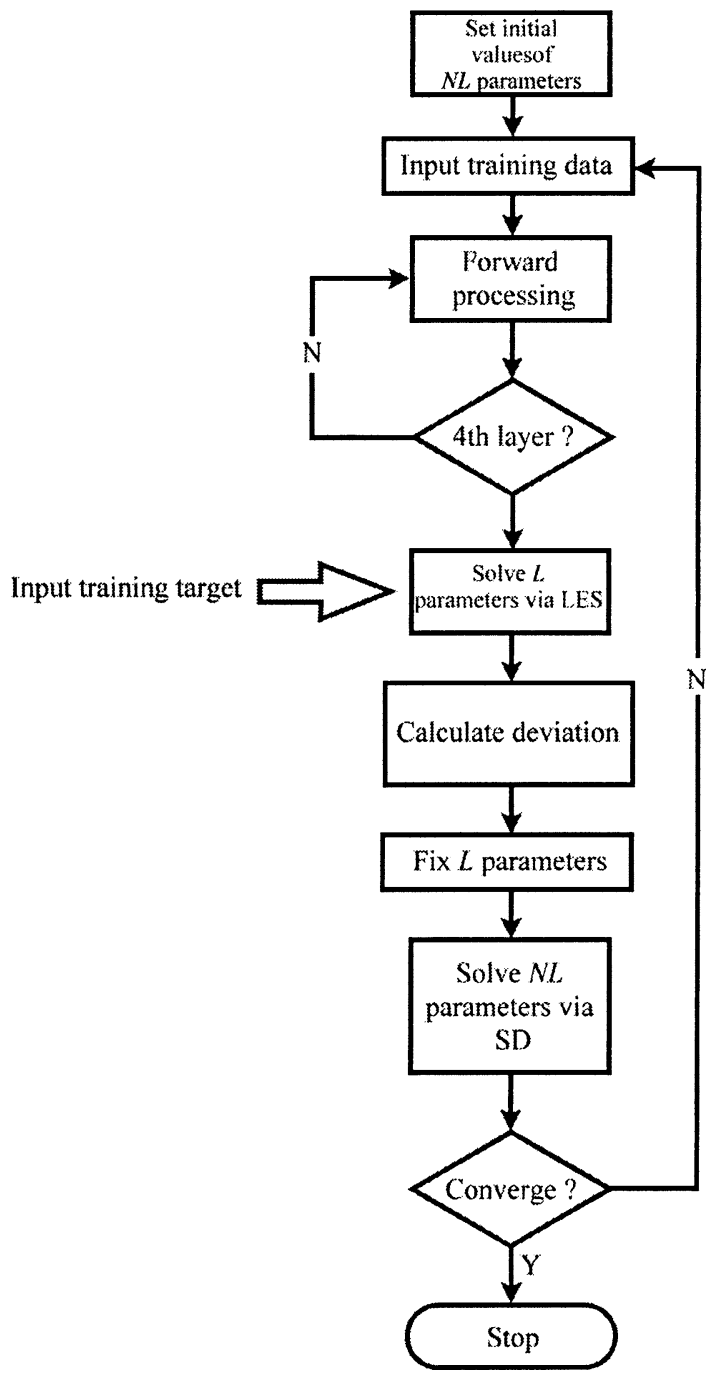

Fig. 2 Flowchart of hybrid learning algorithm process of hybrid learning algorithm is shown in Fig. 2.

\section{Experiment}

The experiment apparatus was composed of a vertical machining center (JohnFord, SV45) and sensing units. Sensing units were thermal sensors and a displacement sensor. Thermocouples (K-type) were employed as thermal sensors for detecting temperature variation in the machine structure, and the capacitance sensor was the displacement sensor used for detecting spindle drift errors on the $X$-, $Y$-, and $Z$ - axes. Eleven thermocouples were mounted at critical points on the machine to detect temperature ascents (Fig. 3). Sensors T1 and T2 provided temperature readings on the machine column; sensors $\mathrm{T} 7$ and T9 measured temperatures on the nut and leadscrew bearing of the $X$-axis; sensors T4 and T8 measured temperatures on the nut and leadscrew bearing of the $Z$-axis; sensor T3 measured the temperature on the working ta-

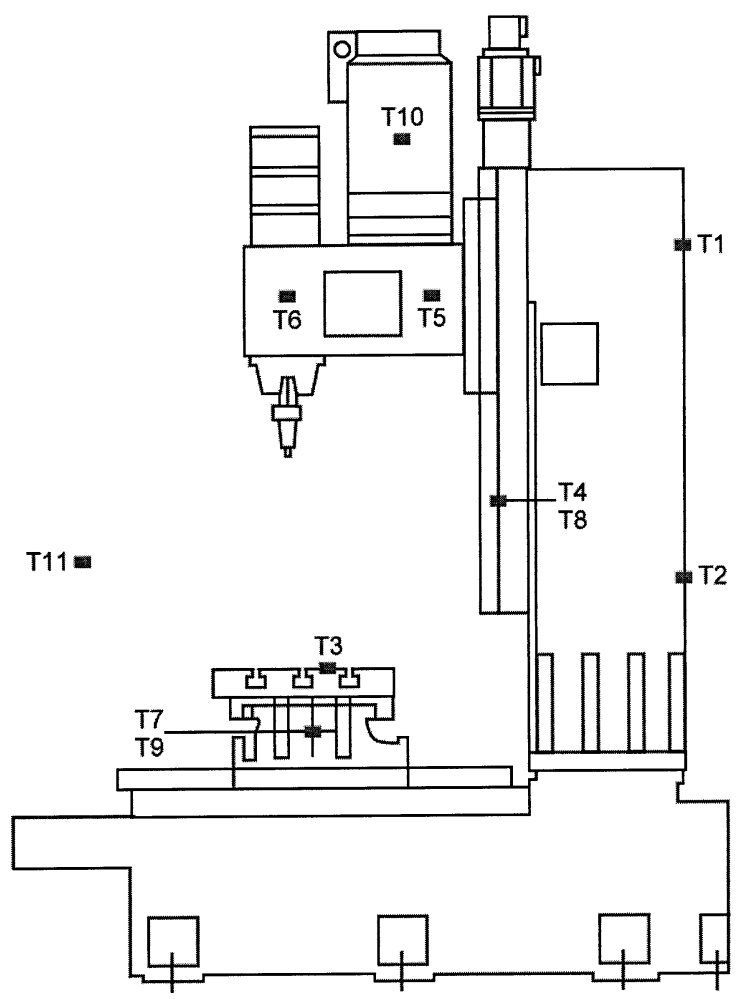

Fig. 3 Thermocouple locations on the machine

Table 1 Test conditions

\begin{tabular}{||l|l|l|l||}
\hline \hline Speed(rpm) & $\begin{array}{l}\text { Operation } \\
\text { time(min) }\end{array}$ & $\begin{array}{l}\text { Feed rate } \\
(\mathrm{mm} / \mathrm{min})\end{array}$ & Note \\
\hline 3000 & 90 & 1500 & Warm-up \\
\hline 0 & 60 & 0 & Cool-down \\
\hline 4200 & 70 & 3000 & Warm-up \\
\hline 0 & 70 & 0 & Cool-down \\
\hline 2400 & 120 & 2000 & Warm-up \\
\hline 0 & 70 & 0 & Cool-down \\
\hline
\end{tabular}


ble; sensors T6 and T5 obtained temperatures on the front and rear portions of the spindle mount respectively; sensor T10 measured temperature on the spindle motor; sensor T11 determined the environmental temperature.

To investigate the machinery's thermal behavior, experiments were performed under designated conditions. Operation conditions were divided into three classes to consider the actual environment in the industrial shop (Table 1).

\section{Modeling and Discussion}

\subsection{Thermal behavior of machine tool}

The temperature ascents at selected critical points on machine and the thermal drifts of spindle nose in the $X$-, $Y$ - and $Z$ - directions were measured synchronously using the experiment apparatus and test conditions described previously. Figure 4 shows measurement results for state of ascent in temperature at different selected points. Noticeably, the maximum temperature ascent occurs at the spindle motor (T10), reaching $16^{\circ} \mathrm{C}$ after 225 minutes of operation. Figure 5 shows the variation in thermal deformation of the spindle over time. The maximum thermal drift occurred at the spindle nose in the $Z$-direction, which is $-100 \mu \mathrm{m}$ after 225 minutes of operation, and then ap-

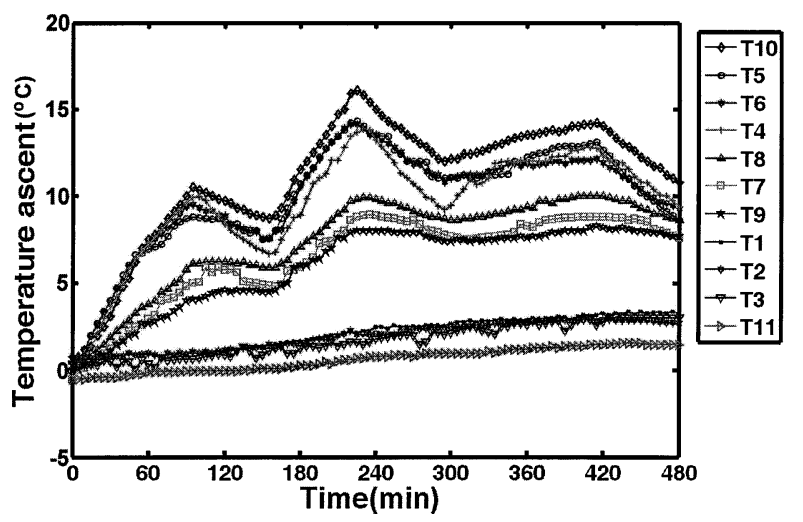

Fig. 4 Variation of temperature ascent at critical points on machine

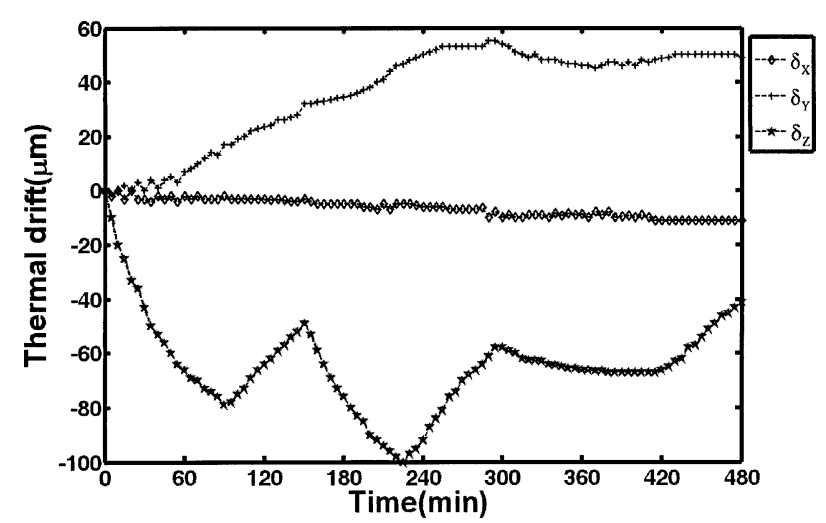

Fig. 5 Variation of the thermal drift of spindle noze in the $X, Y$, and $Z$ directions $\left(\delta_{X}, \delta_{Y}\right.$, and $\left.\delta_{Z}\right)$ proximately keeps at this value when the machine is in a thermally balanced state.

\subsection{Influence weighting of temperature ascent at various critical points}

According to the $\operatorname{GM}(1, N)$ model of grey system theory, using all measured temperature ascents $(\mathrm{T} 1 \sim \mathrm{T} 11)$ as the major variables (sequences) $x_{2}^{(0)} \sim x_{12}^{(0)}$ and the thermal deformation of spindle nose in the $Z$ direction $\left(\delta_{Z}\right)$ as the target variables (sequences) $x_{1}^{(0)}$, the norm values of influence coefficient matrix $\hat{a}$ can be obtained by Eq. (11) as $\left|b_{2}\right|=0.04,\left|b_{3}\right|=0.16,\left|b_{4}\right|=1.35,\left|b_{5}\right|=0.09,\left|b_{6}\right|=0.44$, $\left|b_{7}\right|=0.56,\left|b_{8}\right|=0.9,\left|b_{9}\right|=1.17,\left|b_{10}\right|=0.72,\left|b_{11}\right|=0.92$, and $\left|b_{12}\right|=0.82$, indicating the influence weighting of T1T11 against $\delta_{Z}$, respectively. The resulting influence ranking sequences are: Rank (T3) $>$ Rank (T8) > Rank (T10) $>\operatorname{Rank}$ (T7) > Rank (T11) > Rank (T9) > Rank (T6) > Rank (T5) $>\operatorname{Rank}$ (T2) $>\operatorname{Rank}$ (T4) $>\operatorname{Rank}$ (T1) (Fig. 6). According to the relative norm levels of $b_{2} \sim b_{12}$, the lowranking temperature ascents (T6, T5, T2, T4 and T1) can be neglected, and the high-ranking temperature ascents (T3, T8, T10, T7, T11, and T9) can be used in the following modeling step to map the temperature ascent against thermal error.

\subsection{Thermal error modeling}

The six high-ranking temperature ascents (T3, T8, T10, T7, T11, and T9) are chosen as input variables of fuzzy set, and the thermal deformations of the spindle nose in the $Z$ and $Y$ directions are adopted as target variables. Each temperature ascent uses three membership functions to describe its relationship with thermal drift. The initial generalized bell functions were used to describe the membership grade of these temperature ascents (Fig. 7).

In the fuzzy rule libraries, the input variables are T3, T8, T10, T7, T11, and T9; the thermal drift of spindle nose in the $Z$ and $Y$ directions $\left(\delta_{Z}, \delta_{Y}\right)$ are used as output variables. A $3 \times 3 \times 3 \times 3 \times 3 \times 3$ array of rule libraries is then constructed. The obtained rule libraries for each temperature ascent to $\delta_{Z}$ or $\delta_{Y}$ have 15 rules (Table 2). After setting the initial parameter values in the ANFIS, the error between the output and expected values can be computed,

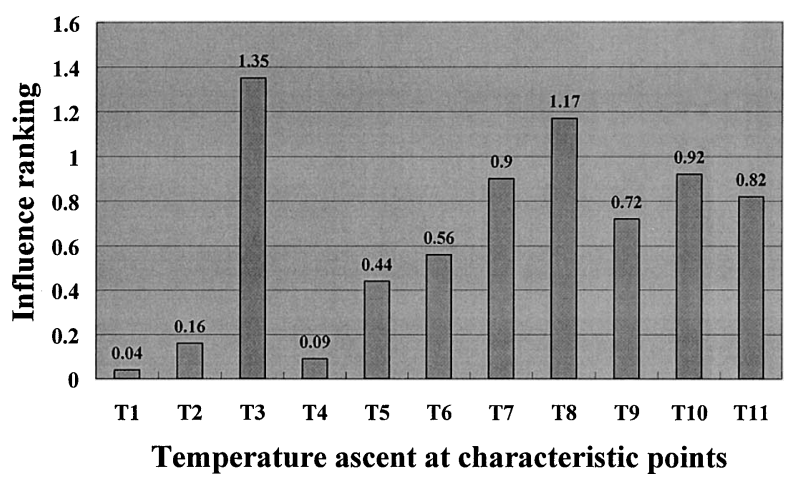

Fig. 6 Influence ranking of temperature ascent at critical points 


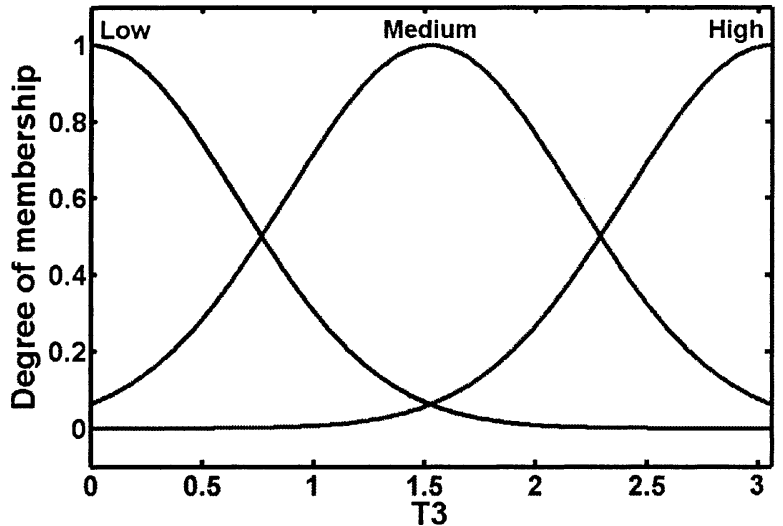

(a)

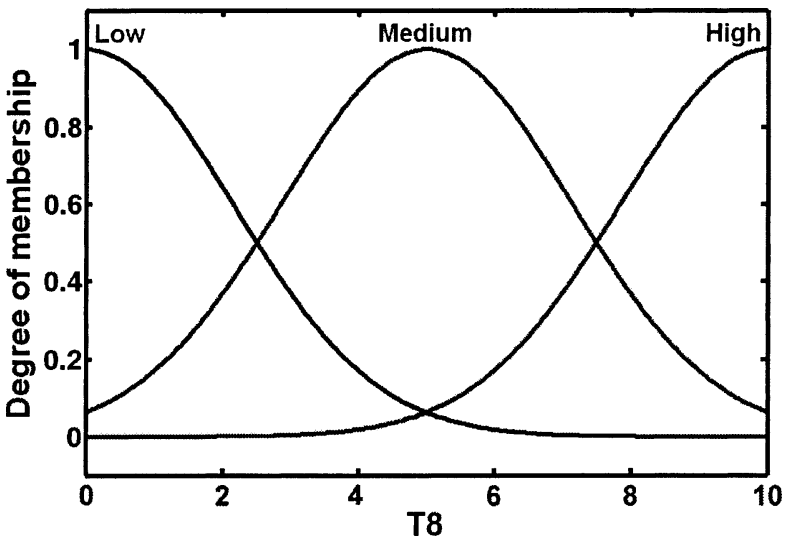

(c)

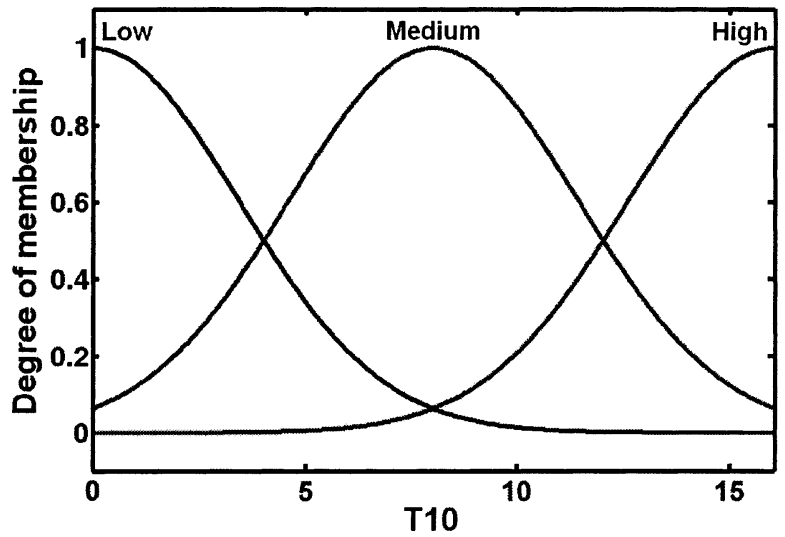

(e)

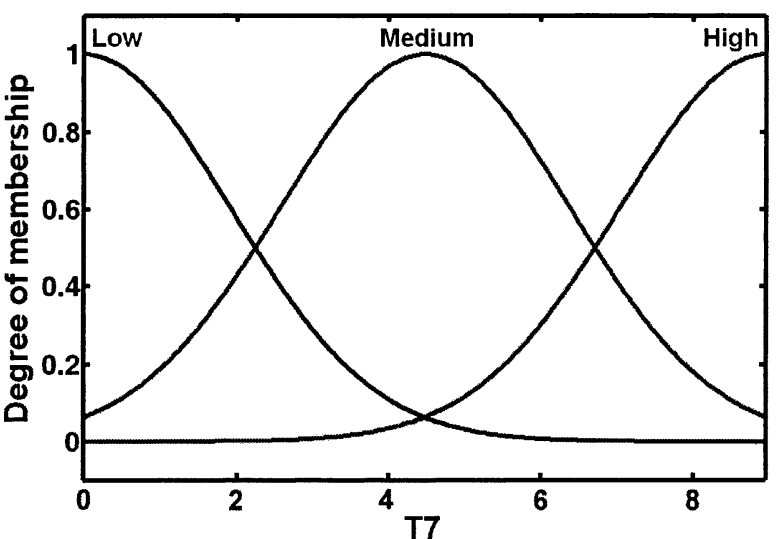

(b)

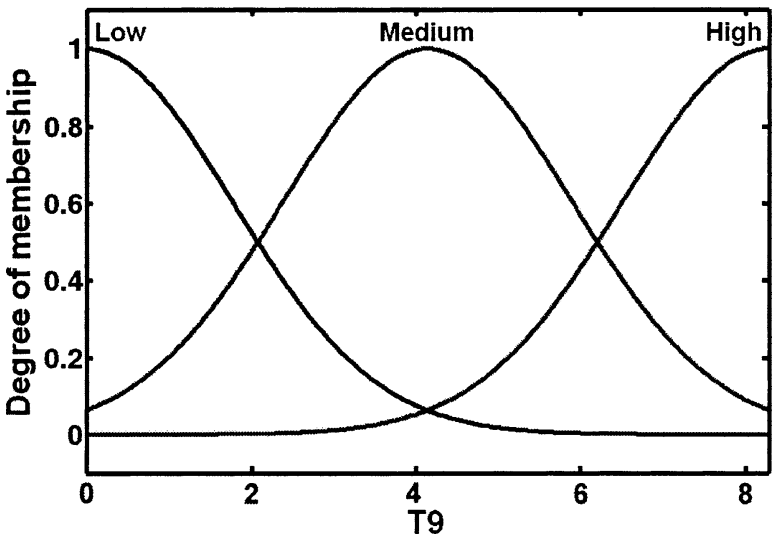

(d)

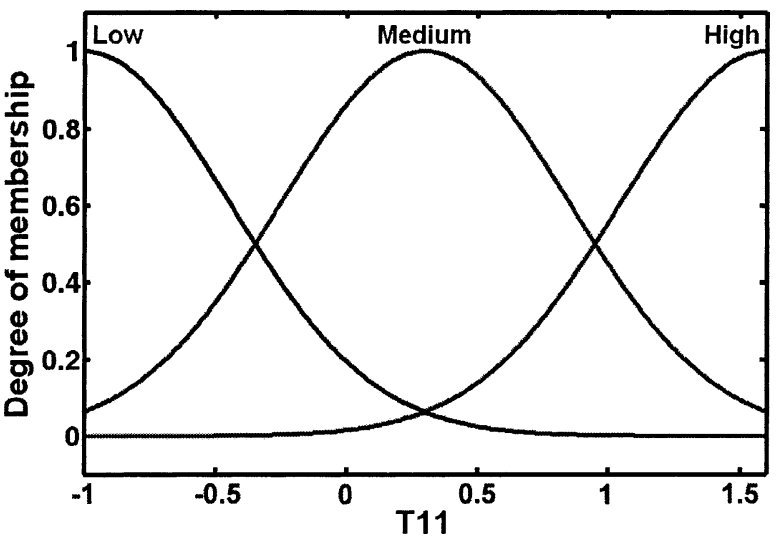

(f)

Fig. 7 Initial settings of membership functions of T3, T7, T8, T9, T10, and T11

and the input membership functions are modified using a hybrid learning scheme. Both $\delta_{Z}$ and $\delta_{Y}$ are trained simultaneously. Supervised training requires the training pair of each input vector (i.e., the temperature ascent) with an output target vector (i.e., the thermal drift). Usually an ANFIS network is trained by a training set that includes many training pairs collected from all test conditions if possible. In this research, the experimental data of 480 training pairs were collected, and 384 data pairs of them were used as training basis while the rest of them (96 data pairs) were used as checking basis. The learning factors of all membership functions are 0.001 .

Using $\delta_{Z}$ as the training target and the hybrid learning algorithm to train the ANFIS network, 79 epochs are required to perform training with a final mean-square convergent error of $0.037 \mu \mathrm{m}$. Table 3 presents the analytical results for comparisons of the midpoint and width of the membership function before and after modification. Figure 8 shows the corrected membership functions of T3, T8, T10, T7, T11, and T9.

Similarly, using the same six high-ranking temperature ascents as input variables and thermal drift of the 
Table 2 Fuzzy libraries (L: Low, M: Medium, H: High, S: Safe, RD: Ready to reduce temperature, HD: Reduce temperature immediately)

\begin{tabular}{|c|c|c|c|c|c|c||}
\hline \hline If T3 is & And T7 is & And T8 is & And T9 is & And T10 is & And T11 is & Then $\delta_{Z}\left(\delta_{Y}\right)$ is \\
\hline \hline L & L & L & L & L & L & S \\
\hline L & M & M & L & L & M & S \\
\hline L & M & L & H & L & M & S \\
\hline M & H & L & L & M & L & S \\
\hline H & L & L & M & L & M & S \\
\hline M & M & M & M & M & M & RD \\
\hline M & L & M & L & M & L & RD \\
\hline M & L & M & L & M & M & RD \\
\hline M & M & H & L & L & M & RD \\
\hline H & M & M & H & M & M & RD \\
\hline H & H & H & H & H & H & HD \\
\hline H & M & H & M & H & L & HD \\
\hline H & H & H & M & M & M & HD \\
\hline M & H & H & M & H & H & HD \\
\hline L & M & H & H & H & H & HD \\
\hline
\end{tabular}

Table 3 Comparisons of midpoint and width of the membership function for $\delta_{Z}$ before and after correction

\begin{tabular}{|c|c|c|c|c|c|c|c|}
\hline & \multicolumn{2}{|c|}{ Low } & \multicolumn{2}{|c|}{ Medium } & \multicolumn{2}{|c|}{ High } \\
\hline & & $\begin{array}{c}\text { Middle } \\
\text { point }\end{array}$ & Width & $\begin{array}{c}\text { Middle } \\
\text { point }\end{array}$ & Width & $\begin{array}{c}\text { Middle } \\
\text { point }\end{array}$ & Width \\
\hline \multirow[b]{2}{*}{ T3 } & Initial value & 20.1 & 0.6285 & 21.58 & 0.6285 & 23.06 & 0.6285 \\
\hline & $\begin{array}{l}\text { Modified } \\
\text { value }\end{array}$ & 20.12 & 0.712 & 21.76 & 0.3919 & 23.12 & 0.4893 \\
\hline \multirow[b]{2}{*}{ T7 } & Initial value & 20 & 1.9 & 24.48 & 1.9 & 28.95 & 1.9 \\
\hline & $\begin{array}{l}\text { Modified } \\
\text { value }\end{array}$ & 20.04 & 1.957 & 24.54 & 1.909 & 29.06 & 1.765 \\
\hline \multirow[b]{2}{*}{ T8 } & Initial value & 20.6 & 1.996 & 25.3 & 1.996 & 30 & 1.996 \\
\hline & $\begin{array}{c}\text { Modified } \\
\text { value }\end{array}$ & 20.02 & 2.155 & 25.12 & 2.234 & 30.1 & 2.061 \\
\hline \multirow[b]{2}{*}{ T9 } & Initial value & 20.1 & 1.741 & 24.2 & 1.741 & 28.3 & 1.741 \\
\hline & $\begin{array}{c}\text { Modified } \\
\text { value }\end{array}$ & 20.02 & 1.751 & 24.31 & 1.897 & 28.37 & 1.727 \\
\hline \multirow[b]{2}{*}{ T10 } & Initial value & 20.8 & 3.249 & 28.45 & 3.249 & 36.1 & 3.249 \\
\hline & $\begin{array}{c}\text { Modified } \\
\text { value }\end{array}$ & 20.01 & 3.434 & 28.03 & 3.338 & 36.13 & 3.32 \\
\hline \multirow[b]{2}{*}{ T11 } & Initial value & 19.5 & 0.4459 & 20.55 & 0.4459 & 21.6 & 0.4459 \\
\hline & $\begin{array}{l}\text { Modified } \\
\text { value }\end{array}$ & 19.14 & 0.651 & 20.58 & 0.441 & 21.66 & 0.5077 \\
\hline
\end{tabular}

spindle nose in the $Y$ direction $\left(\delta_{Y}\right)$ as the output variable, the rule libraries with the same dimension and rule numbers as those for can be established (Table 2). In total, 80 epochs are required for training and a final mean-square convergent error of $0.039 \mu \mathrm{m}$ is reached. Table 4 lists the comparison results for the midpoints and widths of membership function before and after modification.

The maximum absolute deviations for $\delta_{Z}$ and $\delta_{Y}$ between measurement and prediction for the trained ANFIS are $0.02 \mu \mathrm{m}$ and $0.05 \mu \mathrm{m}$, respectively. These comparison results indicate that a good prediction performance by ANFIS can be achieved using trained data. The following study examines prediction ability under other test conditions.

\section{4 Model performance (test at real-cutting condi- tion)}

Since the capacitance-type displacement sensor is unsuitable for measuring thermal drift of the spindle under real-cutting conditions, the length of Renishaw's cutting tool is applied to set up the probe system and measure the spindle's thermal deformation during cutting. This cutting tool system (TS27R) comprises a contact probe module, holder assembly, an MI8 interface module, and power supply unit. The operational conditions are as follows: (1) end milling with 6 flutes and an $80 \mathrm{~mm}$ in diameter cutter; (2) spindle speed $700 \mathrm{rpm}$; (3) feed rate $1200 \mathrm{~mm} / \mathrm{min}$; (4) cut depth $3 \mathrm{~mm}$; (5) reciprocating zigzag cutting; and, (5) cutting material: medium carbon steel S45C.

The temperature information read by the K-type thermocouple is sent to the temperature management program on a personal computer. The compensation value is testified in the cutting experiment for 8 hours. Experimental results show that the ANFIS model can provide a good compensation result. Figure 9 presents the comparison of the thermal drift before and after compensation via ANFIS. The maximum absolute value of $e_{Z}$ does not exceed $9.2 \mu \mathrm{m}$.

\section{Concluding Remarks}

The ANFIS strategy and $\operatorname{GM}(1, N)$ scheme of the grey system theory were applied to the thermal error modeling of a CNC vertical machining center. The following conclusions are drawn for this study.

(1) The thermal error methodological ANFIS applied in this study combines the advantages of fuzzy logic and artificial neural network. Good prediction accuracy and robustness were attained.

( 2 ) The proposed ANFIS modeling approach uses the hybrid learning rule, which is a combination of steepest descent (SD) and the least-square estimator (LES) methods, to train the measured data. This hybrid learning scheme has the benefit of fast convergence during training and, therefore, can significantly shorten modeling time.

( 3 ) The proposed ANFIS model shows good prediction performance. Thermal deformation of the spindle nose in the $Z$ direction can be reduced from $80 \mu \mathrm{m}$ to $<9.2 \mu \mathrm{m}$ under real cutting tests using this modeling scheme.

( 4 ) To minimize the number of point needed to monitor temperature and quickly obtain a correlation between thermal drift of the spindle and temperature ascent, the $\mathrm{GM}(1, N)$ model of grey system theory was applied and its performance is promising.

( 5 ) The proposed fast, accurate and robust modeling scheme can benefit development of a machine's heat error compensation model prior to a tool machine leaving manufacturing plants.

(6) The thermal error compensation technique proposed in this study can be applied to any CNC machine tool as the error model parameters are only calculated mathematically. 


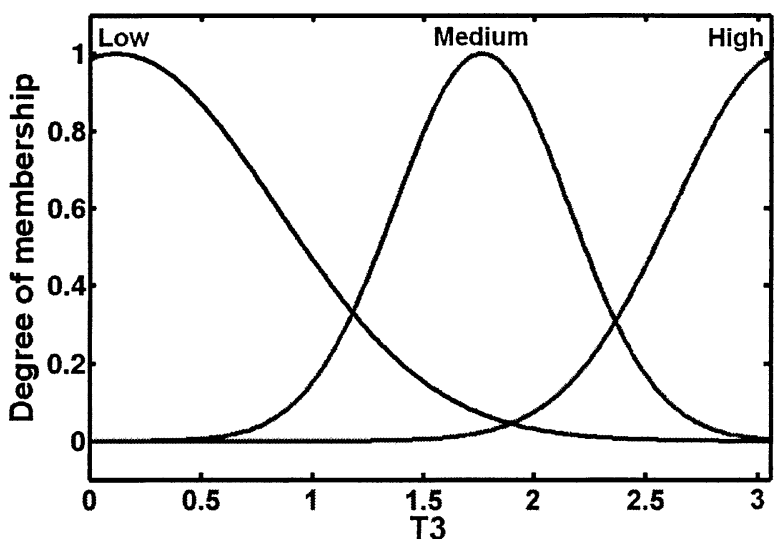

(a)

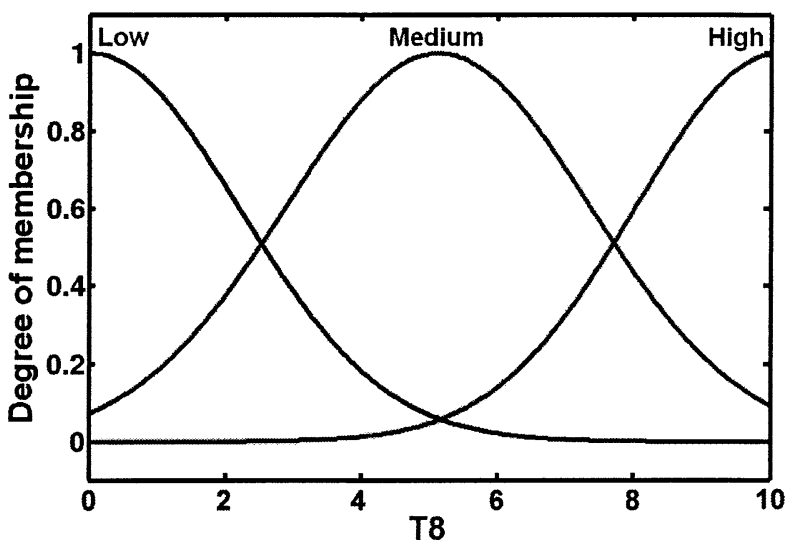

(c)

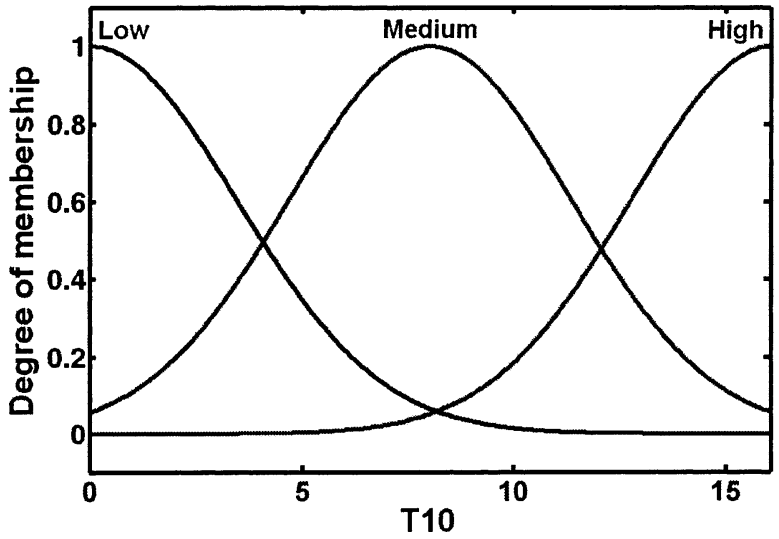

(e)

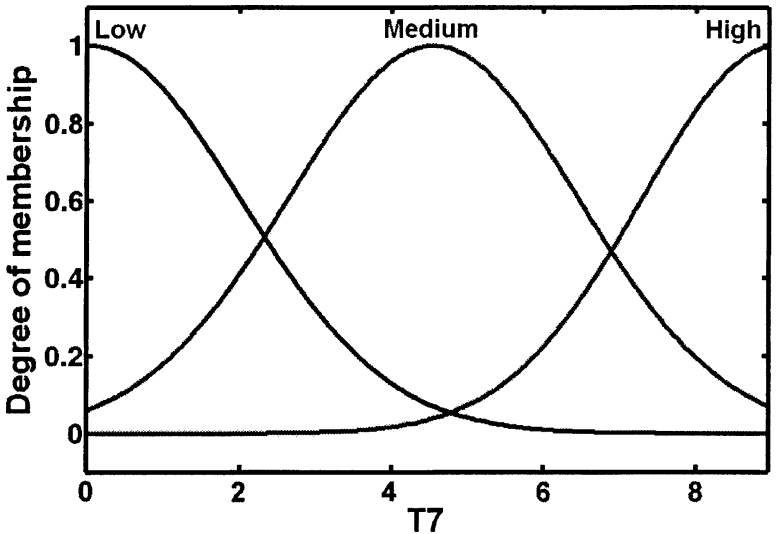

(b)

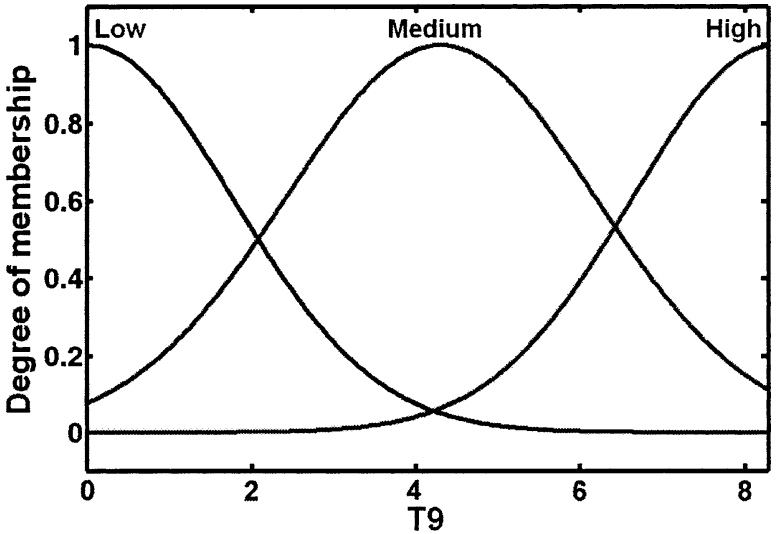

(d)

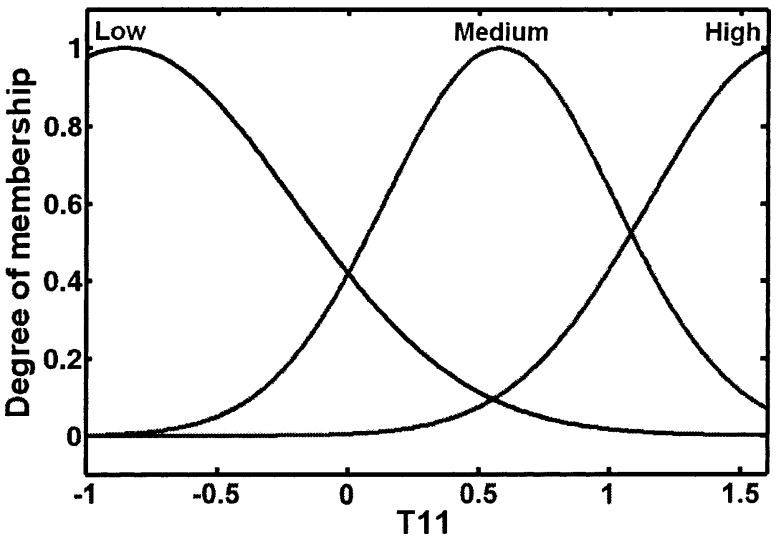

(f)

Fig. 8 Corrected membership functions of T3, T7, T8, T9, T10, and T11 against $\delta_{Z}$

\section{Acknowledgement}

The authors would like to thank the National Science Council of the Republic of China, Taiwan, for financially supporting this research under Contract No.NSC93-2218E-275-003.

\section{References}

( 1 ) Weck, M. and Zangs, L., Computing the Thermal Behavior of Machine Tools Using the Finite Element Method-Possibilities and Limitations, Proc. of 16th MTDR Conf., Vol.16 (1975), pp.185-194.
(2) Moriwaki, T., Thermal Deformation and Its on-Line Compensation of Hydrostatically Supported Precision Spindle, Annals of the CIRP, Vol.37, No.12 (1988), pp.283-286.

( 3 ) Yang, S., Yuan, J. and Ni, J., Accuracy Enhancement of a Horizontal Machining Center by Real-Time Error Compensation, Journal of Manufacturing Systems, Vol.15, No.2 (1996), pp.113-118.

(4) Janeczko, J., Machine Tool Thermal Distortion Compensation, Proceedings of the 4th Biennial International Machine Tool Technology Conference, (1988).

( 5 ) Yang, S., Yuan, J. and Ni, J., Accuracy Enhancement 
Table 4 Comparisons of midpoint and width of the membership function for $\delta_{Y}$ before and after correction

\begin{tabular}{||c|c|c|c|c|c|c|c||}
\hline \hline \multicolumn{2}{|c|}{} & \multicolumn{2}{c|}{ Low } & \multicolumn{2}{c|}{ Medium } & \multicolumn{2}{c||}{ High } \\
\cline { 2 - 8 } & $\begin{array}{c}\text { Middle } \\
\text { point }\end{array}$ & Width & $\begin{array}{c}\text { Middle } \\
\text { point }\end{array}$ & Width & $\begin{array}{c}\text { Middle } \\
\text { point }\end{array}$ & Width \\
\hline \multirow{3}{*}{ T3 } & Initial value & 20.1 & 0.6285 & 21.58 & 0.6285 & 23.06 & 0.6285 \\
\cline { 2 - 8 } & $\begin{array}{c}\text { Modified } \\
\text { value }\end{array}$ & 20.06 & 0.7508 & 21.56 & 0.5547 & 23.19 & 0.4702 \\
\hline \multirow{3}{*}{ T7 } & Initial value & 20 & 1.9 & 24.48 & 1.9 & 28.95 & 1.9 \\
\cline { 2 - 8 } & $\begin{array}{c}\text { Modified } \\
\text { value }\end{array}$ & 20 & 1.91 & 24.49 & 1.889 & 28.99 & 1.869 \\
\hline \multirow{3}{*}{ T8 } & Initial value & 20.6 & 1.996 & 25.3 & 1.996 & 30 & 1.996 \\
\cline { 2 - 8 } & $\begin{array}{c}\text { Modified } \\
\text { value }\end{array}$ & 20 & 2.122 & 25.05 & 2.191 & 30.02 & 2.123 \\
\hline \multirow{3}{*}{ T9 } & Initial value & 20.1 & 1.741 & 24.2 & 1.741 & 28.3 & 1.741 \\
\cline { 2 - 8 } & $\begin{array}{c}\text { Modified } \\
\text { value }\end{array}$ & 20.1 & 1.768 & 24.19 & 1.808 & 28.31 & 1.745 \\
\hline \multirow{2}{*}{ T10 } & Initial value & 20.8 & 3.249 & 28.45 & 3.249 & 36.1 & 3.249 \\
\cline { 2 - 8 } & $\begin{array}{c}\text { Modified } \\
\text { value }\end{array}$ & 20 & 3.418 & 28.03 & 3.365 & 36.1 & 3.366 \\
\hline \multirow{2}{*}{ T11 } & Initial value & 19.5 & 0.4459 & 20.55 & 0.4459 & 21.6 & 0.4459 \\
\cline { 2 - 8 } & $\begin{array}{c}\text { Modified } \\
\text { value }\end{array}$ & 19.08 & 0.6831 & 20.38 & 0.5203 & 21.79 & 0.1485 \\
\hline \hline
\end{tabular}

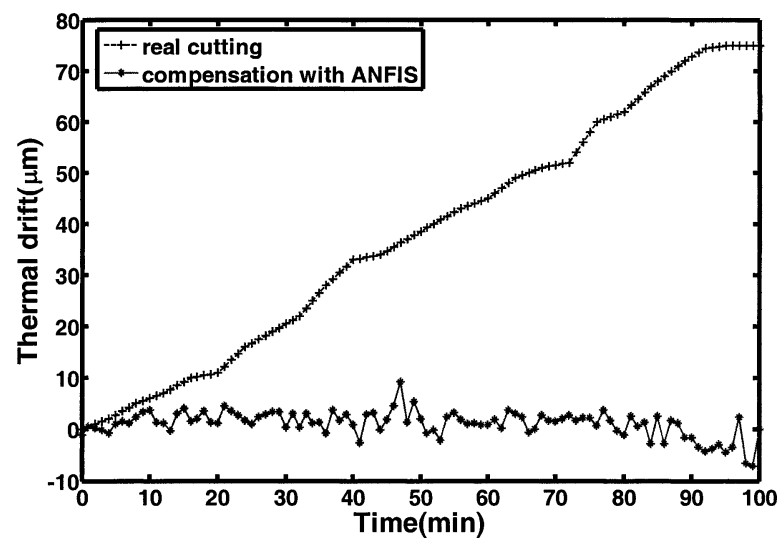

Fig. 9 Thermal drift before and after compensation at realcutting test condition

of a Horizontal Machining Center by Real-Time Error Compensation, J. Manufacturing System, Vol.15, No.2 (1996), pp.113-118.

(6) Chen, J.S., Computer-Aided Accuracy Enhancement for Multi-Axis CNC Machine Tool, Int. J. Mach. Tools Manufact., Vol.35, No.4 (1995), pp.593-605.

( 7 ) Chen, J.S., A Study of Thermally Induced Machine Tool Errors in Real Cutting Conditions, Int. J. Mach. Tools Manufact., Vol.36, No.12 (1996), pp.1401-1411.

( 8 ) Chen, J.S., and Chiou, G., Quick Testing and Modeling of Thermally-Induced Errors of CNC Machine Tools, Int. J. Mach. Tools Manufact., Vol.35, No.7 (1995), pp.1063-1074.

( 9 ) Srivastava, A.K., Veldhuis, S.C. and Elbestawit, M.A., Modeling Geometric and Thermal Errors in a FiveAxis CNC Machine Tool, Int. J. Mach. Tools and Manufac., Vol.35, No.9 (1995), pp.1321-1339.

(10) Li, S., Zhang, Y. and Zhang, G., A Study of PreCompensation for Thermal Errors of NC Machine Tools, Int. J. Mach. Tools and Manufac., Vol.37, No.12
(1997), pp.1715-1719.

(11) Chen, J.S., Fast Calibration and Modelling of Thermally Induced Machine Tool Errors in Real Machining, Int. J. Mach. Tools and Manufac., Vol.37, No.2 (1997), pp.159-169.

(12) Wang, Y., Compensation for the Thermal Error of a Multi-Axis Machining Centre, ASME Trans. J. Materials Processing Technology, Vol.75 (1998), pp.45-53.

(13) Yang, M. and Lee, J., Measurement and Prediction of Thermal Errors of a CNC Machining Centre Using Two Spherical Balls, ASME Trans. J. Materials Processing Technology, Vol.75 (1998), pp.180-189.

(14) Mize, C.D. and Ziegert, J.C., Neural Network Thermal Error Compensation of a Machining Center, J. International Societies for Precision Engineering and Nanotechnology, Vol.24 (2000), pp.338-346.

(15) Lee, Jin-Hyeon, Lee, Jae-Ha and Yang, Seung-Han, Thermal Error Modeling of a Horizontal Machining Center Using Fuzzy Logic Stragedy, J. Manufacturing Processes, Vol.3, No.2 (2001), pp.120-127.

(16) Lee, J.H. and Yangt, S.H., Statistical Optimization and Assessment of a Thermal Error Model for CNC Machine Tools, Int. J. Mach. Tools and Manufac., Vol.42 (2002), pp.147-155.

(17) Du, Z.C., Yang, Z.Q. and Xue, B.Y., Modeling Approach of Regression Orthogonal Experiment Design for the Thermal Error Compensation of a CNC Turning Center, J. Materials Processing Technology, Vol.125 (2002), pp.619-623.

(18) Ramesh, R., Mannan, M.A. and Poo, A.N., Thermal Error Measurement and Modeling in Machine Tools. Part I. Influence of Varing Operating Conditions, Int. J. Mach. Tools and Manufac., Vol.43 (2003), pp.391404.

(19) Yang, H. and Ni, J., Dynamic Modeling for Machine Tool Thermal Error Compensation, J. Manufacturing Science and Engineering, Vol.125 (2003), pp.245-254.

(20) Kurtoglu, A., The Accuracy Improvement of Machine Tools, CIRP Ann., Vol.39, No.1 (1990), pp.417-419.

(21) Chen, J.S., Yuan, J., Ni, J. and Wu. S.M., Thermal Error Modeling for Volumetric Error Compensation, Proceedings, ASME Winter Annual Meeting, PED-Vol.55 (1992), pp.113-125.

(22) Lo, C., Optimal Modeling of Thermal Error Compensation for Machine Tool Error Compensation, S.M. Wu Symposium, (1994), pp.61-67.

(23) Yang, H. and Ni, J., Dynamic Modeling for Machine Tool Thermal Error Compensation, J. Manufacturing Science and Engineering, Vol.125 (2003), pp.245-254.

(24) Jang, J.S.R., Sun, C.T. and Mizutani, E., Neural-Fuzzy and Soft Computing, (1997), Prentice-Hall Inc., Simon \& Schuster/A Viacom Company.

(25) Tseng, F.M., Tzeng, G.H. and Yuan, B., The Comparison of Four Kinds of Prediction Methods: ARIMA, Fuzzy Time Series, Fuzzy Regression Time Series, and Grey Forecasting-An Example of the Production Value Forcast of Machinery Industry in Taiwan, 1997 Second Conference on Grey Theory and Applications (Taiwan), (1997), pp.53-68. 